\title{
Discontinuous Usage Intention of Millennials in Using Facebook: The Role of SNS Exhaustion Mediates Social Overload
}

\author{
Putu Laksmita Dewi Rahmayanti and Ni Nyoman Kerti Yasa
}

\begin{abstract}
Social Networking Sites (SNS) or commonly called social media is an online service that aims to build social relationships with users who share their interests and activities. Percentage of Facebook users decreased during 2018 from January 2018 which was initially $75.5 \%$ to $66.3 \%$ in December 2018. Users complain about the excessive influence of SNS on their lives and react in various forms of behavior to stop using services. Non-continuous use as a user behavior towards stress due to SNS fatigue and social overload. The sample used is 60 respondents which are determined using the purposive sampling method. The data collection technique utilized is by questionnaires with the Likert scale measurement method, while the data are analyzed using the path analysis technique. The research results show that the social overload on SNS exhaustion and SNS exhaustion variable on discontinuous usage intention have a positive and significant influence but social overload on discontinuous usage intention have a positive but non significant effect. Likewise, SNS exhaustion is able to mediate the influence of social overload on discontinuous usage intention. Users can actively control their behavior to avoid potential negative results caused by social overload. Social media providers must effectively prevent the emergence of negative emotions from users by providing a system that gives users to manage whatever information they can receive and share only with a few people so that users do not receive information about their friends on Facebook excessively.
\end{abstract}

Index Term-Social Overload, SNS Exhaustion, Discontinuous Usage Intention, Facebook

\section{INTRODUCTION}

Social Networking Sites (SNS) or commonly called social media is an online service that aims to build social relationships with users who share their interests and activities [16]. Leading social media sites and applications such as Facebook, WhatsApp, WeChat, and Twitter each have 2.1 billion, 1.5 billion, 1 billion, and 336 million active users [21]. Various forms of social media have enriched users and enabled many uses and capabilities to create platforms for building and maintaining social relations [20]. Many SNSs have experienced rapid growth while also facing major challenges. For example, based on data obtained from [26] where the percentage of Facebook users decreased during 2018 from January 2018 which was initially $75.5 \%$ to $66.3 \%$ in December 2018 which can be seen in Figure 1.

Putu Laksmita Dewi Rahmayanti, Faculty of Economic and Business Udayana University (email: laksmita72@gmail.com)

Ni Nyoman Kerti Yasa, Faculty of Economic and Business Udayana University (email: kertiyasa@unud.ac.id)



Figure 1. Decreasing the Percentage of Facebook Users in 2018 Worldwide

Research from [23] shows that Facebook applications have been removed by young users. In the third quarter of 2018, 44 percent of young users aged 18-29 years had deleted the Facebook application from their cellphones. At present, the growth of Facebook's monthly user numbers comes from older users. This situation threatens the loss of 2 million Facebook users from the age of 24 and under. Because, they have moved to other social media such as Instagram and Snapchat. Based on the pre-survey conducted for the people aged 18-29 years in the city of Denpasar, it was found that 25 of the 30 people surveyed stated that they had not used Facebook in the past 1 week. Based on these data it can be concluded that Facebook users from the millennial generation began to decline in using Facebook. Facebook management must pay attention to the causes of users who are millennial generation starting to intend not to continue using Facebook. When users begin to stop using social media, providers lose their key assets because users are a source of financial benefits [5]. Discontinues usage intention or intention to stop using an application is a decision of the user to stop using a system and will not return to use which is relevant if the user has a free choice [29].

Users complain about the excessive influence of SNS on their lives and react in various forms of behavior to stop using services [9]. The number of messages received by users increases with the number of social relationships that are formed in social media [20]. As a result, social media users may be faced with a growing number of social requests that require some form of reaction. This raises questions about the consequences of increasing the use of SNS on the lives of users [3]. On the one hand, social engagement through SNS can benefit SNS users, who experience more social support than non-SNS users [6]. On the other hand, users can be drawn into tiring social situations. In particular, possible social relations in SSNs may be because they give too much social support on SNS to individuals found on their social networks because of a sense of obligation to respond to requests for social support. This is called the phenomenon of social overload. Social overload is a negative perception of the use of SNS when users receive too many social support requests and feel they 
provide too much social support to other individuals embedded in their virtual social networks [18]. Social overload from too many social interactions and related pressures during the use of SNS can lead to behaviors to stop using SNS [19]. But according to research conducted by [15] gives results that in his research social overload does not have a direct influence on discontinuous usage intention.

The intention to stop using social media usually occurs when users begin to get bored in using social media [17]. These users usually have high motivation and freedom to stop using social media because they try to avoid stressful situations by changing their behavior [2]. Non-continuous use as a user behavior towards stress due to SNS fatigue and social overload [18]. The concept of "social network fatigue" to explain the behavior of dismissal of use by users in connection with Facebook [25]. They concluded that negative feelings, boredom, and fatigue caused by the use of SNS lead to user behavior to stop using.

Based on the background of existing problems and a research gap found, the main problem is how the influence of social overload on discontinuous usage intention mediated by SNS exhaustion.

\section{THEORETICAL BACKGROUND AND HYPOTHESES}

\section{A. Social overload and its influence on SNS exhaustion}

Easy access to social media allows people to connect anywhere and anytime. Continuous exposure to social networks makes people feel that they provide excessive social support. This feeling of fatigue occurs when a virtual social request exceeds what the user feels is still within comfortable limits to be given [4]. Excessive communication demands can distract and distract individuals from their daily work and evoke feelings of distraction and frustration [8]. When someone has to give social support to someone's social networking friends, users may be tired of adjusting to social norms and then changing their response decisions when facing too many requests for social support [7]. Finally, social perceptions of overload are usually due to disturbed self-reactions to social demands, or compulsive use of SNS, which is found to have a negative effect and indirect stress [12]. There is a series of studies on fatigue, which are defined as fatigue with excess social burden related to SNS which is partly due to the pressure of social norms which reveal that social overload is a factor that contributes to SNS exhaustion [14], [18]. In the context of SNS, [19] found that social overload is important in influencing stress in this case called SNS exhaustion. We argue that social overload will have a positive and significant effect on exhaustion SNS.

H1: Social overload has a positive and significant effect on SNS exhaustion

\section{B. Social overload and its influence on discontinuous usage intention}

In the study of [19] stated that social overload included in the measurement dimensions of SNS-stress creators had an effect on discontinuous usage intentions. In addition, other studies have found a relationship that excessive use of SNS can cause a decrease in satisfaction; and they consider it may be ultimately related to the termination of the use of SNS [11], [31]. Then, they continue to explore possible factors for disconnected usage behavior; they found "perceived overload", caused by excessive amounts of some SNS features beyond acceptable user levels, might be the predecessor of this phenomenon where one dimension of perceived overload was social overload [10], [18], [32]. But according to [15] states that social overload does not directly and positively influence the discontinuous usage intention.

H1: Social overload has a positive and significant effect on discontinuous usage intention

\section{SNS exhaustion and its influence on discontinuous usage intention}

SNS exhaustion refers to the feeling of weariness of users from using SNS because of its negative effects, psychological tension, or other potential effects [1]. According to previous research, users who are exhausted in doing things begin to grow intentions to change their behavior [24] and intentions to change the current situation [26], which in turn reflect high intentions to stop behavior stress [32]. Therefore, given that when using SNS users become stressed is problematic behavior [30] and SNS users also experience negative results, such as fatigue might motivate individuals to stop using SNS [18]. Research conducted by [25], based on in-depth qualitative interviews, authors find individuals who experience fatigue in social networking tend to reduce the intensity of use, take short breaks or actually leave the SNS. [19] and [13] indicated that when SNS users experience higher levels of fatigue and frustration, the more likely they are to stop using SNS. We argue that users who are exhausted using SNS will develop an intention to stop using SNS.

H3: SNS exhaustion has a positive and significant effect on discontinuous usage intention

\section{The role of SNS exhaustion mediates effect of social overload on discontinuous usage intention}

Excessive use causes social overload, information overload, and SNS sources become dissatisfied and regret encourages users to decide to stop SNS [22]. In the existing literature, social media fatigue is usually regarded as a result of social overload, and further leads to intention to stop using [25], [18], [33].

H4: SNS exhaustion mediates effect of social overload on discontinuous usage intention

\section{Methodology}

This study includes the type of research using associative methods, in which to determine the cause and effect of variables that influence the variables affected. This study discusses the influence of the role of SNS Exhaustion mediating the influence of social overload on discontinuous usage intention. The location of the research chosen by researchers was in the city of Denpasar. The research object used in this study was SNS Exhaustion, social overload, and discontinuous usage intention. The population in this study is the millennial generation that uses Facebook in the city of Denpasar. The sample used amounted to 60 respondents millennial generation.

The data collection method used in this study uses a questionnaire, which is a number of questions that were asked to respondents to then be filled in according to the respondents' perceptions of the object of research. 
Questionnaires were distributed to millennials who used Facebook in Denpasar City. Measurement of answers from respondents was measured using a Likert scale. The data analysis technique in this study uses the classical assumption test and path analysis.

\section{RESUlTS AND DisCUSSION}

The characteristics of the respondents in this study were profiles of 60 respondents who participated in filling out the questionnaire. Profile of respondents explained gender, last education, employment and their duration when using social media. TABLE 1. explains that male respondents are fewer than female respondents where male respondents are $40 \%$ percent while female respondents are $60 \%$ percent. Based on the latest education level, the majority of respondents had a high school / equivalent education level of 63.3 percent, then a diploma of 13.3 percent, while the S1 was 23.3 percent. When viewed from the type of work, the majority of respondents worked as students by 60 percent, then as private employees by 21.7 percent, then entrepreneurs 11.7 percent and followed by other types of work, military / police and civil servants of 3,3 percent and 3.3 percent. Based on their duration in using social media most of them use social media for more than 3 hours a day, then for 1-3 hours a day which is $35 \%$, and for less than 1 hour a day which is $15 \%$

TABLE I: Characteristics of Respondents

\begin{tabular}{|c|c|c|c|c|}
\hline No & Variable & Classification & Total & Percentage \\
\hline \multirow[t]{3}{*}{1} & Gender & Male & 24 & $40 \%$ \\
\hline & & Female & 36 & $60 \%$ \\
\hline & \multicolumn{2}{|l|}{ Total } & 60 & $100 \%$ \\
\hline \multirow[t]{4}{*}{2} & Last Education & High School & 38 & $63,3 \%$ \\
\hline & & Diploma & 8 & $13,3 \%$ \\
\hline & & Bachelor & 14 & $23,3 \%$ \\
\hline & & Total & 60 & $100 \%$ \\
\hline \multirow[t]{6}{*}{3} & Occupation & Student & 36 & $60 \%$ \\
\hline & & Civil servant & 2 & $3,3 \%$ \\
\hline & & $\begin{array}{l}\text { Private } \\
\text { employees }\end{array}$ & 13 & $21,7 \%$ \\
\hline & & Entrepreneur & 7 & $11,7 \%$ \\
\hline & & Military/Police & 2 & $3,3 \%$ \\
\hline & Total & & 60 & $100 \%$ \\
\hline \multirow[t]{4}{*}{4} & Duration of using & $<1$ hour & 9 & $15 \%$ \\
\hline & within 1 day & 1-3 hours & 21 & $35 \%$ \\
\hline & & $>3$ hours & 30 & $50 \%$ \\
\hline & & Total & 60 & $100 \%$ \\
\hline
\end{tabular}

Source: Computed Primary Data, 2019

Validity test aims to check whether the questionnaire as a research instrument is appropriate to measure what you want to measure. Correlation value between item scores with total items is then compared to critical $r$. If the item correlation is greater $r$ critical $(0.30)$ then the instrument can be said to be valid (Sugiyono, 2014: 177).

TABLE II: The Instrument Validity Test Results for the Social Overload Variable

\begin{tabular}{|c|c|c|c|}
\hline No & Indicator & $\mathrm{rc}_{\text {alculated }}$ & Description \\
\hline 1 & $\mathrm{X} 1$ & 0.829 & Valid \\
\hline 2 & $\mathrm{X} 2$ & 0.877 & Valid \\
\hline 3 & X3 & 0.854 & Valid \\
\hline 4 & X4 & 0.763 & Valid \\
\hline
\end{tabular}

Source: Computed Primary Data, 2019

TABLE III: The Instrument Validity Test Results for the SNS Exhaustion Variable

\begin{tabular}{ccccc}
\hline No & & Indicator & $\mathrm{rc}_{\text {alculated }}$ & Description \\
\hline 1 & Y1.1 & 0.847 & Valid \\
2 & Y1.2 & 0.930 & Valid \\
3 & Y1.3 & 0.869 & Valid \\
4 & Y1.4 & 0.908 & Valid \\
\hline
\end{tabular}

Source: Computed Primary Data, 2019

TABLE IV: The Instrument Validity Test Results for the Discontinuous Usage Intention Variable

\begin{tabular}{|c|c|c|c|}
\hline No & Indicator & $\mathrm{rc}_{\text {alculated }}$ & Description \\
\hline 1 & Y2.1 & 0.932 & Valid \\
\hline 2 & $\mathrm{Y} 2.2$ & 0.932 & Valid \\
\hline 3 & Y2.3 & 0.862 & Valid \\
\hline 4 & $\mathrm{Y} 2.4$ & 0.859 & Valid \\
\hline
\end{tabular}

Source: Computed Primary Data, 2019

Reliability test aims to determine the extent to which the consistency of the measuring instrument used. Reliability is measured using the Cronbach's Alpha method, the value of an instrument is said to be reliable if the variable size is greater 0.60 [28]. Reliability test at this research table is shown in Table V.

TABLE V: Research Instrument Reliability Test Results

\begin{tabular}{lll}
\hline Variable $_{\mathrm{x}}$ & Alpha Cronbach & Description \\
\hline Social Overload & 0.851 & Reliable \\
SNS Exhaustion & 0.909 & Reliable \\
Discontinuous Usage Intention & 0.918 & Reliable \\
\hline Source Computed Primary Data, 2019 &
\end{tabular}

Source: Computed Primary Data, 2019

To find out the overall assessment of research variables, it will be seen from the average score with the following criteria: $1.00-1.79=$ Very Poor. $1.80-2.59=$ Poor. 2.60 - 3.39 = Pretty High. 3,40 - 4,19 = High. 4,20 $5,00=$ Very High. Based on the results of the study can be seen the responses of respondents from each indicator of each variable as follows: Variable social overload, with a total average of 3.92 can be stated that in general respondents experienced excessive social exposure when using Facebook. SNS exhaustion variables, with a total average of 3,18 can be stated that in general respondents feel pretty tired when using Facebook. Discontinuous usage intention variable has an average of 4.03 can be stated that in general the respondents have a high intention to discontinue using Facebook.

\begin{tabular}{lcccc}
\multicolumn{4}{c}{ TABLE VI: Result of Path Analysis Structure 1 } \\
\hline \multicolumn{1}{c}{ Variable } & $\begin{array}{c}\text { Standardized } \\
\text { Coefficients }\end{array}$ & $\begin{array}{c}\text { Std. } \\
\text { Error }\end{array}$ & $\begin{array}{c}\text { Statisti } \\
\mathrm{ct} \mathrm{t}\end{array}$ & Sig. t \\
\hline (Constant) & & 0,694 & 9,841 & 0,00 \\
& & & & 0 \\
Social Overload & 0,748 & 0,044 & 8,589 & 0,00 \\
(X) & & & & 0 \\
R Square & 0,560 & & & \\
Statistic F & 73,775 & & \\
Sig. F & 0,000 & & \\
\hline Source: Computed Primary Data, 2019 & &
\end{tabular}

Based on the results of Table IV, the equation of structure 1 and the standard error value are as follows:

Structure 1

$\mathrm{Y}_{1}=\beta_{2} \mathrm{X}_{1}+_{+} \mathrm{e}_{1}$

$\mathrm{Y}_{1}=0,748 \mathrm{X}_{1}+\mathrm{e}_{1}$

$$
\begin{aligned}
\varepsilon_{1}\left(\text { error }_{1}\right) & =\sqrt{1-R^{2}} \\
& =\sqrt{1-0,560} \\
& =0,663
\end{aligned}
$$

\begin{tabular}{|c|c|c|c|c|}
\hline Variable & $\begin{array}{l}\text { Standardized } \\
\text { Coefficients }\end{array}$ & $\begin{array}{l}\text { Std. } \\
\text { Error }\end{array}$ & $\begin{array}{c}\mathrm{t} \\
\text { statistic }\end{array}$ & Sig. $\mathrm{t}$ \\
\hline
\end{tabular}

TABLE VII: Result of Path Analysis Structure 2 


\begin{tabular}{|c|c|c|c|c|}
\hline (Constant) & & 2,182 & 1,642 & $\begin{array}{c}0,10 \\
6\end{array}$ \\
\hline Social Overload & 0,279 & 0,127 & 1,848 & 0,076 \\
\hline $\begin{array}{l}(\mathrm{X}) \\
\text { SNS Exhaustion } \\
(\mathrm{Y} 1)\end{array}$ & 0,417 & 0,253 & 2,762 & 0,008 \\
\hline R Square & 0,427 & & & \\
\hline F Statistic & 21,216 & & & \\
\hline Sig. F & 0,000 & & & \\
\hline
\end{tabular}

Based on the results of Table $\mathrm{V}$, the equation of structure 2 and the standard error value are as follows:

Structure 2

$\mathrm{Y}_{1}=\beta_{3} \mathrm{M}_{1}+\beta_{1} \mathrm{X}_{1}+\mathrm{e}_{2}$

$\mathrm{Y}_{2}=0,279 \mathrm{Y}_{1}+0,417 \mathrm{X}_{1}+\mathrm{e}_{2}$

$e_{2}($ error 2$) \quad=\sqrt{1-R^{2}}$

$=\sqrt{1-0,427}$

$=0,757$

Direct effect: the effect of the Social Overload variable $(\mathrm{X})$ on SNS Exhaustion $(\mathrm{Y} 1)$ is $\beta 1=0.748$; the effect of the SNS Exhaustion variable (Y1) on Discontinuous Usage Intention (Y2) is $\beta 2=0.417$; the effect of Social Overload variable $(\mathrm{X})$ on Discontinuous Usage Intention (Y2) is $\beta 3=0.279$.

Indirect effect; The influence of Social Overload (X) on Discontinuous Usage Intention (Y2) with SNS Exhaustion (Y1) as mediating variable:

Indirect effect $=\beta_{1} \times \beta_{2}$

$$
\begin{aligned}
& =0,748 \times 0,417 \\
& =0,312
\end{aligned}
$$

Total effect; The total effect of Social Overload (X) on Discontinuous Usage Intention (Y2) through SNS Exhaustion variable (Y1):

Total effect $\quad=\beta_{3}+\left(\beta_{1} \times \beta_{2}\right)$

$$
=0,279+(0,748 \times 0,417)=0,591
$$

Based on the calculation of the effect of error, the result of error effect $1\left(\mathrm{Pe}_{1}\right)$ is 0.781 and error effect $2\left(\mathrm{Pe}_{2}\right)$ is 0.767 . The results of the total determination coefficient are as follows:

$$
\begin{aligned}
\mathrm{R}^{2} \mathrm{~m} & =1-\left(\mathrm{Pe}_{1}\right)^{2}\left(\mathrm{Pe}_{2}\right)^{2} \\
& =1-(0,663)^{2}(0,757)^{2} \\
& =1-(0,44)(0,573)=0,748
\end{aligned}
$$

The total determination value of 0.748 means that 74,8 percent of Discontinuous Usage Intention variation is influenced by variations in Social Overload and SNS Exhaustion while the remaining 25,2 percent is explained by other factors not included in the model.

The p-value of F-test is $\leq 0.05$, this means that Social Overload and SNS Exhaustion have a simultaneous and significant effect on Discontinuous Usage Intention. So, it can be explained that the structural equation model has met the Goodness of Fit requirements through the F-test.

The results of the analysis of the effect of Social Overload on SNS Exhaustion obtained a significance level of Social Overload lower than 0.05 , with a beta coefficient value of 0.748 , it can be shows that Social Overload has a positive and significant effect on SNS Exhaustion. The results of the analysis of the effect of SNS Exhaustion on Discontinuous Usage Intention obtained a significance level of SNS Exhaustion lower than 0.05 , with a beta coefficient value of 0.417 , it can be shows that SNS Exhaustion has a positive and significant effect on Discontinuous Usage Intention. The results of the analysis of the effect of Social Overload on Discontinuous Usage Intention obtained a significance level of Social Overload higher than 0.05 , with a beta coefficient value of 0.279 , it can be shows that Social Overload has a positive and non significant effect on Discontinuous Usage Intention of Generasi milenial yang menggunakan Facebook di Kota Denpasar's consumer. The results of path coefficients in the research hypothesis can be illustrated in Figure 2.

Based on Figure 2 it can be seen that the Social Overload variable has the greatest influence with the path coefficient value of 0.748 on SNS Exhaustion variable, SNS Exhaustion variable also affect the Discontinuous Usage Intention variable with a path coefficient value of 0.417 , Social Overload variable also affect the Discontinuous Usage Intention variable with a path coefficient value of 0.279 , and there is an indirect influence through SNS Exhaustion variable with a path coefficient of 0.312 against Discontinuous Usage Intention variables.

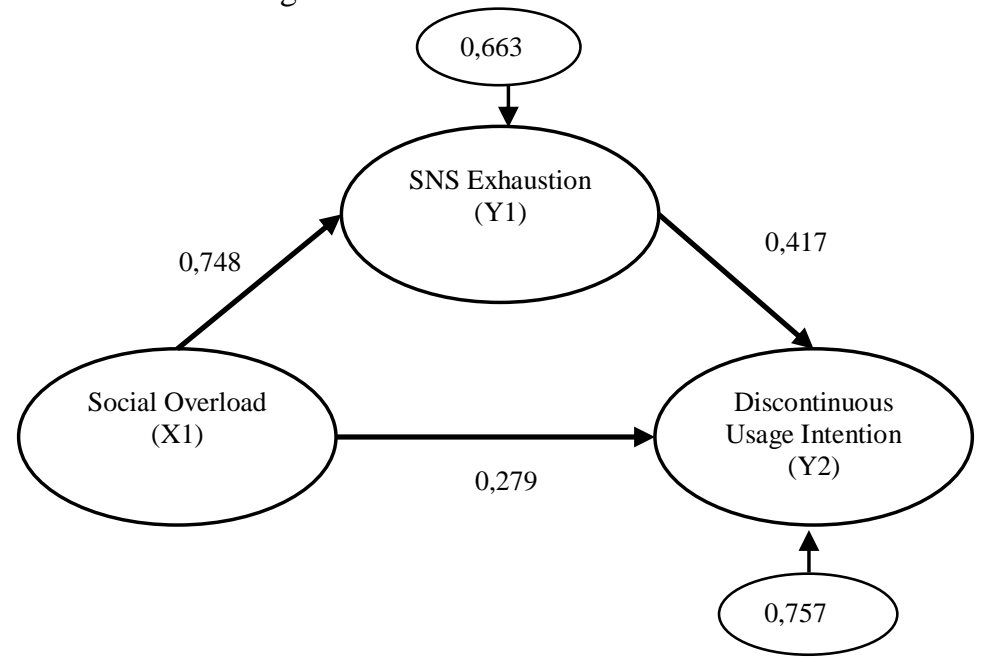

Fig. 2. Final Path Diagram Model

Based on Table VI the direct effect of Social Overload on SNS Exhaustion is 0.748. There is no indirect effect so the total effect is 0.748 . The direct effect of SNS Exhaustion on Discontinuous Usage Intention is 0.417 . There is no indirect effect so the total effect is 0.417 . The direct effect of Social Overload on Discontinuous Usage Intention is 0.279 . The indirect effect of Social Overload on Discontinuous Usage Intention through SNS Exhaustion is obtained from $0.748 \times 0.417=0.312$. Therefore, the effect of the total Social Overload on Discontinuous Usage Intention through SNS Exhaustion is $0.279+0.312=0.592$. This means that there is an indirect effect of the Social Overload variable on Discontinuous Usage Intention through SNS Exhaustion.

TABLE VIII: The Direct Effect, Indirect Effect, and Total Effect Of Social Overload (X), SNS Exhaustion (Y1), snd Discontinuous Usage Intention (Y2) 


\begin{tabular}{cccc}
\hline $\begin{array}{c}\text { Relationship Between } \\
\text { Variables }\end{array}$ & $\begin{array}{c}\text { Direct } \\
\text { Effect }\end{array}$ & $\begin{array}{c}\text { Indirect Effect } \\
(\rho y 1 x) x \\
(\rho y 2 y 1)\end{array}$ & $\begin{array}{c}\text { Total } \\
\text { Effect }\end{array}$ \\
\hline $\begin{array}{c}\text { Social Overload } \rightarrow \text { SNS } \\
\text { Exhaustion }\end{array}$ & 0,748 & - & 0,748 \\
\hline $\begin{array}{c}\text { SNS Exhaustion } \rightarrow \\
\text { Discontinuous Usage Intention }\end{array}$ & 0,417 & - & 0,417 \\
\hline $\begin{array}{c}\text { Social Overload } \rightarrow \\
\text { Discontinuous Usage Intention }\end{array}$ & 0,279 & 0,312 & 0,592 \\
\hline Source: Computed Primary Data, 2019 & &
\end{tabular}

Source: Computed Primary Data, 2019

The Sobel test is a method to test the significance of the indirect effect between the independent variable and the dependent variable mediated by the mediator variable. If the value of $\mathrm{Z}$ is greater than 1.96 (with a confidence level of 95 percent), the mediator variable is assessed significantly. The following table presents the results of the test results.

TABLE IX: Sobel Test Result

\begin{tabular}{lll}
\hline & Value & Description \\
\hline $\mathrm{Z}$ & 2,51 & Mediated \\
\hline Source: Computed Primary Data, 2019 &
\end{tabular}

Based on Table IX, shows that the $\mathrm{Z}$ value result of the Sobel test on the influence of Social Overload variable on Discontinuous Usage Intention mediated by SNS Exhaustion is 2.51 or greater than 1.96 , which means that the SNS Exhaustion variable is considered to significantly mediate the Social Overload variable against Discontinuous Usage Intention.

\section{A. The Influence of Social Overload on SNS Exhaustion}

The results of calculations in Table VI find a level of social overload of $0,000<0,05$ with a beta value of 0,748 so the research hypothesis $\mathrm{H} 1$ accepted this means that Social Overload has a positive and significant effect on SNS Exhaustion in the millennial generation that uses Facebook in Denpasar City. Social Overload measured by indicators cares too much about the conditions of friends on Facebook, too much attention to what my friends share on Facebook, receives too many friend requests, and receives too many messages from friends (or acquaintances) through Facebook proven to be able to increase SNS Exhaustion in the millennial generation that uses Facebook in Denpasar City.

The results of this study are in accordance with the hypothesis formulation which states that Social Overload has a positive and significant effect on SNS Exhaustion in the millennial generation that uses Facebook in the City of Denpasar. This means that the higher the Social Overload is felt, the higher the SNS Exhaustion experienced by the user. The results of this study support the research conducted by [4], [7], [8], [12], [14], [18]

\section{B. The Influence of SNS Exhaustion on Discontinuous Usage Intention}

The calculation results in Table VII. find the significance level of SNS Exhaustion of $0.008<0.05$ with a beta value of 0.417 , the $\mathrm{H} 2$ research hypothesis is accepted, this means that SNS Exhaustion has a positive and significant effect on Discontinuous Usage Intention in millennials who use Facebook in Denpasar City. SNS Exhaustion measured by indicators feels tired when using
Facebook, feeling bored when using Facebook, feeling less interested even though there are new things happening on Facebook, and feeling less concerned with notifications about new things from Facebook proven to be able to increase Discontinuous Usage Intention in millennial generations who uses Facebook in Denpasar City.

The results of this study are in accordance with the hypothesis formulation which states that SNS exhaustion has a positive and significant effect on discontinuous usage intention in the millennial generation that uses Facebook in Denpasar City. This means that the higher the SNS exhaustion is felt, the higher the discontinuous usage intention created in the millennial generation that uses Facebook in the City of Denpasar. References [1], [13], [18], [19], [24], [25], [26], [29], and [33] supported the result of this research.

\section{The Influence of Social Overload on Discontinuous Usage Intention}

The calculation results in Table VII. find a significance level of social overload of $0.070>0.05$ with a beta value of 0.279 , the $\mathrm{H} 3$ research hypothesis is rejected, this means social overload has a positive but not significant effect on discontinuous usage intention in the millennial generation that uses Facebook in Denpasar City. Social overload that is measured by indicators is too concerned with the situation of friends on Facebook, paying too much attention to what my friends share on Facebook, receiving too many friend requests, and receiving too many messages from friends (or acquaintances) through Facebook is not proven to increase discontinuous usage intention for millennial generation that uses Facebook in Denpasar City.

The results of this study oppose the hypothesis formulation which states that social overload has a positive and significant effect on discontinuous usage intention in the millennial generation that uses Facebook in the City of Denpasar and opposes the research conducted by [10], [11], [19], [31], [32]. But this study supports the results of a study conducted by [15] which states that social overload has a positive and not significant effect on discontinuous usage intention. Social overload does not significantly influence the discontinuous usage intention of the millennial generation that uses Facebook in the City of Denpasar, this is because the millennial generation has a tolerance for saturation in accepting higher social interactions because they are used to using social media for a long time in a day, can be seen in the results of the characteristics of respondents where most of the respondents spend $>3$ hours a day using social media so that when they are not at this saturation point, they still continue to use social media as usual.

\section{The role of SNS Exhaustion mediates Social Overload against Discontinuous Usage Intention}

The calculation results obtained by comparison of $\mathrm{Z}$ count value of 2.51> Z table of 1.96, then the H4 research hypothesis is accepted which means that SNS Exhaustion is able to mediate significantly the influence of social overload on discontinuous usage intention. This shows that if the SNS exhaustion increases, the influence of social overload on discontinuous usage intention increases again. The results of this study are in accordance with the hypothesis formulation which states that SNS exhaustion 
mediates the influence of social overload on discontinuous usage intention in the millennial generation that uses Facebook in Denpasar City. The results of this study support the research conducted by [18], [22], [25], [33].

\section{CONCLUSION}

The conclusions of this study when viewed based on the results of the analysis of the study and the results of the discussion are first, social overload has a positive and significant effect on SNS exhaustion in the millennial generation that uses Facebook in the City of Denpasar. This shows that the higher the social overload is felt, the higher the SNS exhaustion is felt. Second, SNS exhaustion has a positive and significant effect on discontinuous usage intention in the millennial generation that uses Facebook in Denpasar City. This shows that the higher the SNS exhaustion is felt then the discontinuous usage intention in the millennial generation that uses Facebook in Denpasar City will be higher.

Third, social overload has a positive and not significant effect on discontinuous usage intention in the millennial generation that uses Facebook in Denpasar City. This shows that the higher the social overload that is felt it will have an effect but not significantly on the millennial generation of discontinuous usage intention that uses Facebook in the City of Denpasar. This is because the millennial generation has a tolerance for boredom in accepting higher social interactions because they are used to using social media for quite a long time in a day, can be seen in the results of the characteristics of respondents where most of the respondents spend $>3$ hours a day in using social media so that when they are not at this saturation point, they still continue to use social media as usual.

Fourth, SNS exhaustion significantly mediates the effect of social overload on discontinuous usage intention. This shows that the higher the social overload that is felt will increase SNS exhaustion, if the SNS exhaustion is increased it will indirectly increase the discontinuous usage intention in the millennial generation that uses Facebook in the City of Denpasar.

Based on the results of research analysis, discussion and conclusions there are several suggestions that can be used as material for consideration in determining policies related to reducing and suppressing discontinuous usage intention in the millennial generation that uses Facebook in Denpasar City and also to users. Users can actively control their behavior to avoid potential negative results caused by social overload. For example, they can be more selective in accepting friend requests on Facebook to avoid meaningless social networking activities.

In addition, they can choose other communication channels such as meeting directly as an alternative to reduce their dependence on social media. This research shows that social overload and SNS exhaustion will lead to cessation behavior to use social media. Such behavior is a problem for social media providers, mainly because they lose market share and profitability is threatened. Social media providers must effectively prevent the emergence of negative emotions from users by providing a system that gives users to manage whatever information they can receive and share only with a few people so that users do not receive information about their friends on Facebook excessively.

\section{REFERENCES}

[1] Ayyagari, R., Grover, V., and Purvis, R. (2011) Technostress: Technological antecedents and implications. MIS quarterly, 35 (4): 831-858.

[2] Beaudry, A., and Pinsonneault, A. Understanding user responses to information technology: A coping model of user adaptation. MIS quarterly, 2005, 493-524.

[3] Brandtzæg, P. B., Følstad, A., \& Mainsah, H. (2012, July). Designing for youth civic engagement in social media. In Proceedings of the IADIS International Conference of Web Based Communities and Social Media (pp. 65-73).

[4] Cao, X., \& Sun, J. (2018). Exploring the effect of overload on the discontinuous intention of social media users: An SOR perspective. Computers in human behavior, 81, 10-18.

[5] Chiu, C.M. and Huang, H.Y. (2014), "Examining the antecedents of user gratification and its effects on individuals' social network services usage: the moderating role of habit", European Journal of Information Systems, available at: www.palgrave-journals.com. ezproxy.lis.nsysu.edu.tw:8080/ejis/journal/vaop/ncurrent/full/ejis201 49a.html\#bib85 (accessed April 29, 2014). 485.

[6] Hampton, K. N. (2011). Comparing bonding and bridging ties for democratic engagement: Everyday use of communication technologies within social networks for civic and civil behaviors. Information, Communication \& Society, 14(4), 510-528.

[7] Jacobson, R.P, Mortensen, C.R, and Cialdini, R.B. (2011). Bodies obliged and unbound: differentiated response tendencies for injunctive and descriptive social norms, Pers. Soc. Psychol. 100 (3). Pp 433-448

[8] Karr-Wisniewski, P., Lu, Y. (2010). When more is too much: operationalizing technology overload and exploring its impact on knowledge worker productivity, Computer Human Behavior, 26 (5), pp 1061-1072

[9] Kelly, B. (2013, June). Using social media to enhance your research activities. In Social media in social research 2013 conference.

[10] Kim, J., \& Lee, J. E. R. (2011). The Facebook paths to happiness: Effects of the number of Facebook friends and self-presentation on subjective well-being. CyberPsychology, behavior, and social networking, 14(6), 359-364.

[11] Kross, E., Verduyn, P., Demiralp, E., Park, J., Lee, D. S., Lin, N., Shablack, H., Jonides, J., and Ybarra, O. (2013). "Facebook Use Predicts Declines in Subjective Well-Being in Young Adults," PloS one (8:8), p. e69841.

[12] LaRose R, Connolly, Lee, K., Li, K.D, dan Hales. (2014). Connection overload? A cross cultural study of the consequences of social media connection. Information System Management. 31 (1). Pp 59-73

[13] Laumer, S., Maier, C., Weitzel, T., and Wirth, J., Drivers and consequences of frustration when using social networking services: A quantitative analysis of Facebook users, in In Proceeding of AMCIS 2015, 2015.

[14] Lee, A.R., Son., S.M., dan Kim, K.K. (2016). Information and communication technology overload and social networking service fatigue: a stress perspective, Comput. Hum. Behav. 55. Pp 51-61

[15] Lim, C., Park, J., Iijima, J., \& Ahn, J. (2017, July). A Study on Social Overload in SNS: A Perspective of Reactance Theory. In PACIS (p. 100).

[16] Luqman, A., Cao, X., Ali, A., Masood, A., \& Yu, L. (2017) Empirical investigation of Facebook discontinues usage intentions based on SOR paradigm. Computers in Human Behavior, 70, 544555.

[17] Maier, C., Laumer, S., Eckhardt, A., \& Weitzel, T. (2012). When Social Networking Turns to Social Overload: Explaining the stress, Emotional Exhaustion, and Quitting Behavior from Social Network sites' Users. In Ecis (p. 71).

[18] Maier, C., Laumer, S., Weinert, C., \& Weitzel, T. (2015a). The effects of technostress and switching stress on discontinued use of social networking services: a study of Facebook use. Information Systems Journal, 25(3), 275-308.

[19] Maier, C., Laumer, S., Eckhardt, A., \& Weitzel, T. (2015b). Giving too much social support: social overload on social networking sites. European Journal of Information Systems, 24(5), 447-464.

[20] Manago, A. M., Taylor, T., \& Greenfield, P. M. (2012). Me and my 400 friends: The anatomy of college students' Facebook networks, their communication patterns, and well-being. Developmental psychology, 48(2), 369.

[21] Murnane, K. (2018). Which social media platform is most popular in the US? Forbes. 
[22] Nawaz, M. A., Shah, Z., Nawaz, A., Asmi, F., Hassan, Z., \& Raza, J. (2018). Overload and exhaustion: Classifying SNS discontinuance intentions. Cogent Psychology, 5(1), 1-18.

[23] Pew Research Centre. (2018). https://www.pewresearch.org/

[24] Podsakoff, P. M., MacKenzie, S. B., Lee, J.-Y., and Podsakoff, N. P. (2003). Common method biases in behavioral research: A critical review of the literature and recommended remedies. Journal of applied psychology, 88 (5): 879.

[25] Ravindran, T., Yeow Kuan, A. C., \& Hoe Lian, D. G. (2014). Antecedents and effects of social network fatigue. Journal of the Association for Information Science and Technology, 65(11), 23062320.

[26] Sonnentag, S., and Frese, M. Stress in organizations. (2003): Wiley Online Library.

[27] Suara. (2019). https://www.suara.com/

[28] Sugiyono. (2014) Metode Penelitian Kuantitatif Kualitatif dan R\&D. Bandung: Alfabeta.

[29] Turel, O., He, Q., Xue, G., Xiao, L., \& Bechara, A. (2014). Examination of neural systems sub-serving Facebook "addiction". Psychological Reports, 115(3), 675-695.

[30] Turel, O. (2015). "Quitting the use of a habituated hedonic information system: a theoretical model and empirical examination of Facebook users." European Journal of Information Systems 24(4): 431-446.

[31] Yamakami, T. (2012). "Towards Understanding Sns Fatigue: Exploration of Social Experience in the Virtual World," Computing and Convergence Technology (ICCCT), 2012 7th International Conference on: IEEE, pp. 203-207.

[32] Zhang, S., Zhao, L., Lu, Y., \& Yang, J. (2015). Get Tired of Socializing as Social Animal? An Empirical Explanation on Discontinuous Usage Behavior in Social Network Services. In PACIS (p. 125).

[33] Zhang, S., Zhao, L., Lu, Y., \& Yang, J. (2016). Do you get tired of socializing? An empirical explanation of discontinuous usage behaviour in social network services. Information \& Management, 53(7), 904-914.

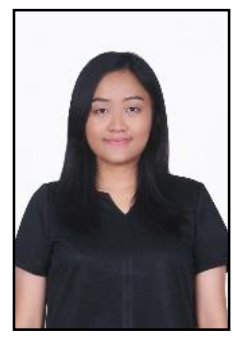

Putu Laksmita Dewi Rahmayanti was born in Denpasar, Bali. She completed her Bachelor of Economic from Udayana University in 2018. She is currently a Master of Management student at Udayana University.

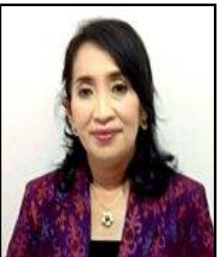

Ni Nyoman Kerti Yasa was born in Denpasar, Bali. She is currently a Lecturer and Researcher at Udayana University. 